\title{
PERSPECTIVA DE MELHORIA DOS PROCESSOS DE TRABALHO EM UM BANCO DE LEITE HUMANO MEDIADO POR USO DE TECNOLOGIA
}

Autores: Roberta de F. da N. Souza ${ }^{[1]}$; Vilani M. A.Nunes ${ }^{[2]}$.

QualiSaúde ${ }^{\circledR}$

\section{INTRODUÇÃO}

No tocante as legislações que regem os Bancos de Leite Humano (BLH), foi elaborada a RDC 171 da ANVISA que os regulamentam como serviço especializado, responsáveis por implementarem ações estratégicas de promoção, proteção e apoio ao aleitamento materno, bem como coleta, seleção, processamento, estocagem e distribuição do leite humano ordenhado (LHO). De acordo com esta RDC, é de competência do BLH registrar as etapas dos processos de trabalho e dispor de um sistema de informação que assegure que os registros estejam disponíveis de forma segura, fazendo-se necessário, assim, o auxílio das tecnologias da informação.

\section{OBJETIVO}

Elaborar e implantar soluções informatizadas para qualificar o processo de trabalho no BLH.

\section{METODOLOGIA}

Trata-se de um estudo exploratório, observacional, descritivo e transversal. Será aplicado no BLH da Maternidade Januário Cicco (MEJC), situada no município de Natal, sendo referência para o Estado do Rio Grande do Norte. A MEJC faz parte dos Hospitais Universitários sob a gestão da Empresa Brasileira de Serviços Hospitalares (EBSERH). A coleta de dados será feita por observação do processo de trabalho, análise das legislações e normas operacionais que regulamentam o BLH e realização da técnica de grupo nominal para priorização das oportunidades de melhoria.

\section{RESULTADOS ESPERADOS}

Contribuir com a melhoria da qualidade das informações, disponibilizando-as de forma acessível e segura, por intermédio de ferramentas informatizadas. Assim, dados estatísticos serão gerados, os quais auxiliarão na tomada de decisão analítica, como também, almeja-se catalogar dados sobre doadoras e receptoras de LHO, com intuito de facilitar a coleta em domicílio, reduzindo custos, bem como criar banco de dados informatizado.

\section{CONCLUSÃO}

Haverá aprimoramento da gestão das atividades que envolvem o BLH, celeridade nos processos de trabalho e adequação às boas práticas de qualidade em serviços de saúde.

\section{REFERÊNCIAS:}

1. BRASIL. Resolução RDC n 171, de 4 de Setembro de 2006. Dispõe sobre o Regulamento Técnico para o funcionamento de Bancos de Leite Humano. Órgão emissor: ANVISA- Agência Nacional de Vigilância Sanitária. Disponível em: http://anvisa.gov.br. Acesso em 10 Jun 2018.

2. Ministério da Saúde. Política Nacional de Informação e Informática em Saúde. Brasília, $2016 . \quad$ Disponível em: http://lovsms.saúde.gov.br/bvs/publicações/politica nacional infor informática saúde 2016.pdf. Acesso em 18 Jun 2018. 